\title{
Editorial
}

\section{Subclinical Hypothyroidism, Pregnancy and the Fukushima Nuclear Power Plant Accident}

\author{
Kazuhiro Takahashi, ${ }^{1,2}$ \\ ${ }^{1}$ Executive Editor, Tohoku Journal of Experimental Medicine, Sendai, Miyagi, Japan \\ ${ }^{2}$ Department of Endocrinology and Applied Medical Science, Tohoku University Graduate School of Medicine, \\ Sendai, Miyagi, Japan
}

In this Issue of Tohoku Journal of Experimental Medicine, Furukawa et al. (2017) reported that elevated thyroid-stimulating hormone (TSH) levels (3.0-10.0 $\mu \mathrm{U} /$ $\mathrm{mL}$ ) were not associated with overall adverse pregnancy outcomes in Japanese women without known medical complications. The authors suggest that effects of subclinical hypothyroidism on pregnancy are different among regions. Iodine is an essential nutrient for thyroid hormone synthesis. Japan is known to have an iodine-rich dietary culture. By contrast, the prevalence of positive thyroid antibodies is lower in low-risk pregnant women in Japan, compared with those outside of Japan (Orito et al. 2009). The findings by Furukawa et al. (2017) are consistent with the previous report by Orito et al. (2009), who showed no apparent adverse effects of subclinical hypothyroidism during early pregnancy on the fetus in healthy Japanese women with dietary iodine excess. Although excess iodine intake may induce hypothyroidism, subclinical hypothyroidism during early pregnancy had no adverse effects on pregnancy outcomes and the fetus in healthy Japanese women in these studies (Orito et al. 2009; Furukawa et al. 2017).

The study by Furukawa et al. (2017), which was performed at hospitals in the suburbs of Tokyo, reminds us of possible adverse effects of the radioactive iodine exposure by the Fukushima Nuclear Power Plant Accident on the thyroid function of residents in Fukushima and its neighboring regions, particularly children and adolescents. The Fukushima Health Management Survey Group performed the comprehensive survey of thyroid ultrasound examinations in subjects aged $\leq 18$ years on March 11, 2011 in Fukushima (Hino et al. 2016; Suzuki et al. 2016a, b). The survey showed a high overall thyroid cancer prevalence of $37.3 / 100,000(0.037 \%)$ in children and adolescents, which can be attributed, however, to mass screening effects (Suzuki et al. 2016b). The Tohoku Journal Experimental Medicine would like to express our sincere appreciation for the Fukushima Health Management Survey Group on this matter. On the other hand, a significant relationship between prevalence of subclinical hypothyroidism and indi- vidual ${ }^{131}$ I thyroid dose due to environmental exposure was reported in a Ukrainian cohort after the 1986 Chornobyl Accident (Ostroumova et al. 2009). To the best of our knowledge, no reports have been available on the prevalence of (subclinical) hypothyroidism after the 2011 Fukushima Accident, although Suzuki et al. (2016a) reported inappropriate suppression of TSH concentrations in young patients with thyroid nodules including thyroid cancer in Fukushima.

Thyroid doses in residents affected by the 2011 Fukushima Accident were more than 1-2 orders of magnitude lower than those by the 1986 Chornobyl Accident (Tokonami et al. 2012). Moreover, contaminated food including dairy food was strictly forbidden to go on the market just after the 2011 Fukushima Accident in Japan. The effect of ${ }^{131} \mathrm{I}$ exposure on the thyroid function may therefore be negligible in Fukushima. However, the evidence on the absence of increased prevalence of (subclinical) hypothyroidism by ${ }^{131} \mathrm{I}$ exposure should be required, particularly in the female children and adolescents for future successful pregnancy and delivery in Fukushima and its neighboring regions.

\section{References}

Furukawa, S., Miyakawa, K., Shibata, J. \& Iwashita, M. (2017) Women with subclinical hypothyroidism are at low risk of poor pregnancy outcome in Japan. Tohoku J. Exp. Med., 242, 167-172.

Hino, Y., Murakami, M., Midorikawa, S., Ohtsuru, A., Suzuki, S., Tsuboi, K. \& Ohira, T. (2016) Explanatory meetings on thyroid examination for the "Fukushima Health Management Survey" after the Great East Japan Earthquake: Reduction of anxiety and improvement of comprehension. Tohoku J. Exp. Med., 239, 333-343.

Orito, Y., Oku, H., Kubota, S., Amino, N., Shimogaki, K., Hata, M., Manki, K., Tanaka, Y., Sugino, S., Ueta, M., Kawakita, K., Nunotani, T., Tatsumi, N., Ichihara, K., Miyauchi, A. \& Miyake, M. (2009) Thyroid function in early pregnancy in Japanese healthy women: relation to urinary iodine excretion, emesis, and fetal and child development. J. Clin. Endocrinol. Metab., 94,1683-1688.

Ostroumova, E., Brenner, A., Oliynyk, V., McConnell, R., Robbins,

Published online July 7, 2017; doi: 10.1620/tjem.242.165.

Correspondence: Kazuhiro Takahashi, M.D., Ph.D., Department of Endocrinology and Applied Medical Science, Tohoku University

Graduate School of Medicine, 2-1 Seiryo-machi, Aoba-ku, Sendai, Miyagi 980-8575, Japan.

e-mail: ktaka-md@med.tohoku.ac.jp 
J., Terekhova, G., Zablotska, L., Likhtarev, I., Bouville, A., Shpak, V., Markov, V., Masnyk, I., Ron, E., Tronko, M. \& Hatch, M. (2009) Subclinical hypothyroidism after radioiodine exposure: Ukrainian-American cohort study of thyroid cancer and other thyroid diseases after the Chornobyl accident (1998-2000). Environ. Health Perspect., 117, 745-750.

Suzuki, S., Nakamura, I., Suzuki, S., Ohkouchi, C., Mizunuma, H., Midorikawa, S., Fukushima, T., Ito, Y., Shimura, H., Ohira, T., Matsuzuka, T., Ohtsuru, A., Abe, M., Yamashita, S. \& Suzuki, S. (2016a) Inappropriate suppression of thyrotropin concentrations in young patients with thyroid nodules including thyroid cancer: The Fukushima Health Management Survey.
Thyroid, 26, 717-725.

Suzuki, S., Suzuki, S., Fukushima, T., Midorikawa, S., Shimura, H., Matsuzuka, T., Ishikawa, T., Takahashi, H., Ohtsuru, A., Sakai, A., Hosoya, M., Yasumura, S., Nollet, K.E., Ohira, T., Ohto, H., et al. (2016b) Comprehensive Survey Results of Childhood Thyroid Ultrasound Examinations in Fukushima in the First Four Years After the Fukushima Daiichi Nuclear Power Plant Accident. Thyroid, 26, 843-851.

Tokonami, S., Hosoda, M., Akiba, S., Sorimachi, A., Kashiwakura, I. \& Balonov, M. (2012) Thyroid doses for evacuees from the Fukushima nuclear accident. Sci. Rep., 2, 507, doi. org/10.1038/srep00507. 